\title{
NEW ZEALAND INTEGRATED FRUIT PRODUCTION FOR PIPFRUIT - CHARTING A NEW COURSE
}

\author{
T.A. BATCHELOR ${ }^{1}$ J.T.S. WALKER ${ }^{2}$, D.W.L. MANKTELOW ${ }^{2}$, \\ N.M. PARK ${ }^{1}$ and S.R. JOHNSON ${ }^{1}$ \\ ${ }^{1}$ NZAFRUIT New Zealand (International), \\ P.O. Box 1101, Hastings \\ ${ }^{2}$ HortResearch, Hawke's Bay Research Centre, \\ PB 1401, Havelock North
}

\begin{abstract}
Integrated Fruit Production (IFP) practices for pipfruit are being adopted by New Zealand growers initially to maintain access to key supermarkets in the UK for about $25 \%$ of our total pipfruit exports. Subsequent advantages of the programme include implementation of more environmentally sustainable pest and disease control practices, reduced pesticide loading in the environment, and compliance with local and international regulatory requirements. The programme was largely successful in the first year of implementation. The methodologies for programme development and technology transfer are described, together with the constraints and opportunities that affect further adoption of the programme.
\end{abstract}

Keywords: Integrated Fruit Production, IFP, pipfruit, implementation, New Zealand

\section{INTRODUCTION}

Under government legislation implemented nearly 50 years ago the New Zealand Apple and Pear Marketing Board (NZAPMB) has the legal power to acquire and sell all pipfruit exported from New Zealand. The NZAPMB is therefore a grower cooperative comprising almost 1600 growers who, in 1997, supplied about 17 million cartons (approximately 300,000 tonnes or less than $2 \%$ of the world's apples) for export to more than 50 countries. Pipfruit from New Zealand is marketed overseas by ENZAFRUIT New Zealand (International) (hereafter referred to as 'ENZAFRUIT'), the marketing division of the NZAPMB.

There are strong imperatives for introducing Integrated Fruit Production (IFP) practices for pipfruit in New Zealand, including those related to ensuring market access and compliance with national and international regulatory requirements and improving sustainability of production.

\section{Market Access and Regulatory Requirements}

The United Kingdom receives approximately $25 \%$ of our apple exports annually so is an important market for ENZAFRUIT. The UK fresh produce retail business is highly concentrated with four retailers controlling $61 \%$ of all fresh fruit and vegetable sales. This provides buyers from these companies with considerable purchasing power and control over supply specifications.

Some UK retailers have specified that pipfruit from New Zealand must be produced following Integrated Crop Management Systems (ICM) (Anon 1993; Anon 1995). Most recently, the Fresh Produce Consortium, or FPC, (a grouping of the retailers in the UK) has developed the FPC Code of Practice (COP) designed to meet UK legislative requirements relating mainly to food safety and pesticide usage. This COP is designed to meet the requirements of six Acts, Regulations and Directives promulgated since 
$1985^{1}$. ENZAFRUIT has been formally requested to agree to abide by the FPC COP that includes compliance with pesticide maximum residue limits (MRLs), recording of pesticide use by growers, verification of compliance with MRLs, and recognition of the importance of Integrated Crop Management (Anon 1997).

\section{Pipfruit industry's pesticide risk management procedures}

ENZAFRUIT has implemented extensive pesticide risk management procedures for ensuring compliance with the MRLs of importing countries. These have resulted in pesticide residues that are either non-detectable or near the limit of detection. This pesticide risk management policy was designed to avoid regulatory, consumer and/or retailer concern with residues in food and is based on:

- Registered numbers for all growers allowing traceability from the packed carton to the orchard producing the fruit;

- Growers permitted to use only those pesticides registered in New Zealand and approved by ENZAFRUIT;

- ENZAFRUIT monitoring MRL requirements and residue concerns in overseas markets;

- ENZAFRUIT setting withholding periods that are generally much longer than the New Zealand requirements:

- ENZAFRUIT releasing a pesticide Wall Chart annually to all growers that shows the approved pesticides and their withholding periods;

- Mandatory completion of Pest Control Record Books (PCRBs) by all growers intending to export pipfruit, recording pesticides applied;

- Computer analysis of every spray entry in the PCRBs to ensure compliance with pesticide Wall Chart specifications; and

- Random residue tests and surveillance residue testing fruit for export from at least $25 \%$ of growers annually.

All pipfruit exports tested since the low-residue programme was introduced in 1991 have complied with the MRL requirements of the importing country and therefore readily meet their sanitary requirements under the international Phytosanitary and Sanitary agreement of GATT.

\section{Market access and sustainability of production}

Pipfruit producers in New Zealand are now being asked by European retailers to grow fruit under the most environmentally-favourable conditions possible in addition to complying with regulatory requirements of the European importing countries. In order to meet the UK ICM criteria, ENZAFRUIT in collaboration with HortResearch, has implemented procedures to encourage pipfruit to be produced following IFP guidelines. Approximately $35 \%$ of European pipfruit is already produced following IFP guidelines (Crosset al. 1995). In the future other supermarkets in EU are also likely insist that their producers supply fruit that follow IFP guidelines.

New Zealand is initially targeting the EU for IFP exports as the phytosanitary requirements are less restrictive than those imposed by the USA and some SE Asian countries. To export to the USA, for example, New Zealand pipfruit producers must apply more pesticides than for fruit destined for Europe in order to avoid quarantine violations. However, the longer term aim for the IFP programme is for fruit to meet the phytosanitary requirements of other markets under a single IFP standard by the 20002001 season. This paper describes the development of the NZ IFP- P programme.

\section{METHODS}

\footnotetext{
${ }^{1}$ Food \& Environment Protection Act 1985 (Part III Pesticides); The Control of Pesticides Regulations 1986; The Pesticides (Maximum Residue Levels in Crops, Food and Feeding Stuffs) Regulations 1994 and amendments; Food Safety Act 1990 Sections 7,8 and 14; Pesticide Residues in Food. Codex Alimentarius Commission Volume 2 and Supplement I to Volume 2, Second Edition 1993 (adopted limits only) and amendments; EC Prohibition Directive 78/117/EEC and amendments.
} 


\section{Programme principles}

New Zealand Integrated Fruit Production - Pipfruit (NZIFP-P) principles were based on European-based guidelines (Avilla 1995), and is defined as: "The economical production of market-quality fruit, giving priority to sustainable methods that maintain consumer confidence and are the safest possible to the environment and human health. NZ IFP-P is a programme based on continuous improvement." The programme is being developed through a very well-structured decision-making process that includes scientific and grower information.

\section{NZ IFP-P Committee}

Sections produced by the Technical Subcommittees must be accepted by the National NZIFP-P Committee before inclusion in the Manual. The Committee consists of 10 growers representing seven regions, one AGCARM representative, one environmentalist, one consumer representative and a horticultural consultancy representative. This committee is chaired by a representative from ENZAFRUIT with two senior scientists from HortResearch as Co-Chairs.

\section{NZ IFP-P Technical Subcommittees}

There are 15 NZ IFP-P Technical Subcommittees, each with 4-10 members, that are responsible for developing the technical content for sections of the NZ IFP-P Manual. Specifications in each section are based on the Principles developed by the NZ IFP-P Committee. The Technical Subcommittees cover: Site, Rootstock, and Variety Selection; Soil Management and Tree Nutrition; Weeds and Understorey Management; Water Management; Tree Training and Management; Spray Application Methods; Pests; Diseases; Orchard Environmental Quality; Industry Operations; Cleaner Production; Workshops, Training and Auditing; Pesticide Rating System; Market Intelligence; and Regulatory. There are currently 43 people from ENZAFRUIT, HortResearch and AgResearch involved in these Technical Subcommittees.

An internal ENZAFRUIT NZ IFP-P Steering Committee has assisted with any supplier-marketing requirements for fruit produced following NZ IFP-P specifications.

The 10 growers on the Committee have formed NZ IFP-P Regional Task Forces in each of their regions. This provides a grower/industry forum for discussion of the Principles and Manual and is the main link between the Committee and growers for comment on the content of any documentation produced.

\section{Timetable for development of Manual}

Growers in the trial programme for the first year evaluated the Pest and Disease sections of the ENZA NZ IFP-P Manual (Anon 1996). The remaining sections are undergoing review and are scheduled for inclusion by 30 June 1997.

An important section covers the Pesticide Rating System which will attach a score to the agrichemical based on known biological and physical criteria (Walkeret al. 1997a). This information will allow growers to select those agrichemicals with the lowest score and least damaging to the environment, and serve as a guide for chemical companies when considering new, or alternative, products for use in the pipfruit industry.

Improvements to the Manual will be considered each year by the relevant Technical Subcommittees before being presented to the National Committee for approval.

\section{Trial NZ IFP-P programme}

The pest and disease performance in the first season of the programme was evaluated on 88 orchards in various regions of New Zealand. The economic performance of these orchards was also compared with a proportion of each supplying fruit following conventional fruit production (CFP) practices.

\section{Technology transfer}

Technology transfer in the NZ IFP-P programme occurred in a three stage process which was found effective by Contant (1990) for changing production practices to reduce pesticides. Grower meetings were held to: 1 . Highlight the problems with current CFP practices; 2 . Outline alternative methodology under development in NZ IFP-P; 3. Instigate a method for continuous learning.

Grower interest in IFP was stimulated some three months prior to implementation of the trial programme by meetings with growers to report on the market access restrictions being imposed by UK supermarkets. Providing growers with persuasive 
reasons for changing production practices was important in stimulating grower interest to adopting the new production strategy (Constant 1990). During this period alternative practices for pest and disease control were being finalised for inclusion in the Manual, and growers were provided with outlines of the proposed control programmes. The programme was three-fold over-subscribed in the first year which was deliberately kept to a small group of growers in order to develop an effective infrastructure for technology transfer.

A "bottom-up" approach using "Two-Weekly Triangles" was developed for technology transfer. Each Triangle group consisted of 10-12 growers, a consultant and a secondary researcher. Each Triangle appointed a Facilitator as the main contact. The growers largely determined the agenda for discussion which was usually the most pressing pest and disease problems facing their orchard at the time. This "bottom-up" approach has been found to be effective elsewhere in promoting adult learning (Rogers 1993), especially where learners are on equal footing with their Facilitators. The programme relied heavily on verbal communication which has been reported by Wearing (1988) to be the most effective method of delivery. Verbal communication included grower-grower discussions in Triangles, discussion between consultant-grower on individual properties, and discussion ENZAFRUIT-grower meetings.

Problems unsolved by Triangle discussion for a particular meeting were quickly referred by the secondary researcher to the primary researcher (the technical expert who took a lead in developing the section for the Manual) who faxed the "Question and Answer" to all Triangle GroupFacilitators. This proved to be an effective, timely and efficient method for providing on-orchard advice to growers involved in the programme.

The Triangle meetings were supplemented with two technical workshops on identification of pests and diseases and monitoring methodology. These workshops were conducted during the season and were attended by growers as well as consultants.

Factors contributing to the success of NZ IFP-P technology transfer included:

- Continuous information supplied to growers during periods when pest and disease control was critical;

- Growers who were philosophically supportive of the aims of the programme and enthusiastic to learn how to implement NZ IFP-P on their own properties;

- Minor financial support from ENZAFRUIT that recognised grower contribution in developing the programme for the subsequent benefit of all growers; and

- Confidence in the scientific capabilities of the researchers who devised the monitoring process and thresholds for pest and disease control.

To accommodate a larger number of growers involved in the second season of the NZ IFP-P programme, grower selected Facilitators for each group will be trained in the technical requirements of the programme and group dynamics. Specialised personnel will be trained to monitor the pest and diseases. ENZAFRUIT is funding a Massey University study on understanding producer characteristics which will be used to design educational programmes to enhance NZ IFP-P adoption. Technical aspects of the programme are under-pinned by approximately $\$ 1.3 \mathrm{~m}$ annually in $\mathrm{R}$ and $\mathrm{D}$ which is aimed at implementing technology related to NZ IFP-P.

\section{RESULTS AND DISCUSSION}

The results of this trial have been reported by Walker et al. (1997b) for pest control and economic comparisons of NZ IFP-P with CFP; and Manktelow et al. (1997) for disease control. In general, these authors report production of export quality fruit with excellent pest control using 35-60\% fewer post-bloom insecticides than CFP. However the costs of pest control was similar in both IFP and CFP due to the additional cost of pest and disease monitoring in the NZIFP-P programme. A reduction in pesticide use should help to decrease the risk of pest resistance and a substantial reduction (88-93\%) in the use of broad spectrum organophosphate pesticides should maximise the potential for biological control.

There are a number of threats to the NZ IFP-P programme that unless addressed could lead to ENZAFRUIT not achieving 100\% grower adoption by the 2000/01 export season. Potential threats to IFP adoption can be divided into technical and logistical 
problems. The key technical problem that this programme seeks to avoid is growers suffering unacceptable pest, disease or other croplosses. Thresholds must be sufficiently conservative for responses and the programme must seek to promote more intelligent use of benign products rather than to bring about arbitrary reductions in agrichemical use. ENZAFRUIT is currently funding the development of a High Pressure Apple Washer (HPAW) designed to remove external arthropods from the surface of the fruit without damaging apple quality or slowing packhouse throughput. The tandem development of the HPAW combined with implementation of narrow-spectrum pest control methods aims to minimise the risks of rejection due to unwanted arthropods.

Given the three year timeframe that ENZA has set for full adoption of the IFP programme, logistical problems probably pose the greatest potential hurdle to the shortterm success of the programme. The greatest of these problems is likely to be the relative returns growers obtain for IFP fruit versus conventionally produced fruit. Fruit for some markets currently receive a premium and it is essential that ENZAFRUIT establishes an IFP fruit payment policy that provides growers with competitive returns. The strongest motivator, without doubt, is financial reward (Cross et al. 1995).

IFP offers long-term benefits of more biologically and economically sustainable production practices. Economic sustainability is envisaged primarily from maintenance of EU access and premiums for high quality fruit. However, with appropriate modifications to the IFP programme by the Pest and Disease Technical subcommittees, the programme should compete directly with current CFP costs and not lead to unacceptable fruit losses. To challenge for ENZAFRUIT is to continue to build integrity into the IFP programme based on an extension of the NZAPMB current risk management practices.

\section{ACKNOWLEDGEMENTS}

The authors acknowledge the assistance of ENZAFRUIT staff Alasdair Robertson; HortResearch staff Howard Wearing, Max Suckling, Graham Burnip, Peter Shaw, Cath Kingston and Peter Lo in the development of the first stage of the NZIFP-P programme, and for extensive discussions with growers; the NZIFP-P Committee including growers Mike Russell, Len Thompson, Jeff Norish, Andrew Malcolm, Chris Bidwell, Wayne King, Vivienne Cruickshank, Audrey Fell-Smith, Peter Antony and George Edy; consultants Andrew Hodson, Craig Hornblow, Roy McCormick and Ross Wilson; consumer representative Melanie Miller; Environmental representative Meriel Watts; AGCARM representatives Brian Smith and Alan Cliffe; and Massey University personnel Stuart Morriss, Ewen Cameron and Heidi Stiefel.

\section{REFERENCES}

Andreae, D., 1996. Environmental Label to Launch in 1998. The Orchardist of New Zealand: 22-23.

Anon., 1993. Sainsbury's policy on the Integrated Crop Management System for environmentally responsible crop production. J Sainsbury plc: $20 \mathrm{pp}$.

Anon., 1994. Guidelines for Integrated Production of Pome Fruits in Europe. Eds: J.V. Cross and E. Dickler Technical Guideline III. Second edition. IOBC wprs Bulletin Anon., 1995. Nature's Choice Code of Practice. Tesco plc: 33pp.

Anon., 1996. New Zealand Integrated Fruit Production - Pipfruit. ENZAFRUIT New Zealand (International), Wellington, New Zealand.

Anon., 1997. The Control of Pesticides - A Code of Practice. Fresh Produce Consortium (UK). Third Edition. 86pp.

Avilla, J., 1995. Tasks and positions of the IOBC/WPRS IP-Commission: An evaluation of the role of IF Guidelines I-III. Pp 11-16In: International Conference on Integrated Fruit Production. IOBC/wprs Bulletin 19(4)F. Polesny, W. Muller and R.W. Olszak (Eds.).

Contant, C.K., 1990. Providing information to farmers for groundwater quality protection. J. Soil Water Conservation 45 (2): 314-317.

Cross, J.V., Bonauer, A., Bondio, B., Clemente, J., Denis, J., Grauslaund, J., Hugeut, C., Jorg, E., Koning, S., Kvale, A., Malavolta, C., Barcelle, R., Morandell, I., Oberhofer, H., Pontalti, M., Polesny, F., Rossini, M., Schenk, A., de Schaetzen, C., and Vilajeliu, 
M. 1995. The current status of integrated pome fruit production in western Europe and its achievements. Pp 11-16. In: International Conference in Integrated Fruit Production IOBC/WPRS Bulletin Vol 19(4).

Manktelow D.W.L, Beresford, R.M., Hodson, A.J., Walker J.T.S., Batchelor T.A., Stiefel, H.E., and Horner, I., 1997. Integrated ffuit production (IFP) for New Zaland pipfruit: evaluation of disease management in a pilot programme. Proc. 50th N.Z. Plant Prot.Conf.: (this volume).

Rogers, E.M., 1993. Adult Education And Agricultural Extension: Some Comparisons. Int. J. Lifelong Learning 12(3): 165-176.

Walker, J.T.S., Hodson, A.J., Batchelor, T.A., Manktelow, D.W., and Tompkins A.R., 1997a. A pesticide rating system for monitoring agrichemical inputs in New Zealand horticulture. Proc. 50th N.Z. Plant Prot. Conf.: (this volume).

Walker, J.T.S., Hodson, A.J., Wearing, C.H., Bradley, S.J., Shaw, P.W., Stiefel, H.E., and Batchelor, T.A. 1997b. Integrated fruit production (IFP) for New Zealand pipfruit: evaluation of pest management in a pilot programme.Proc. 50th N.Z. Plant Prot. Conf.: (this volume).

Wearing, C.H., 1988. Evaluating the IPM implementation process.Ann. Rev. Entomol. 33: 17-38. 